\title{
Improved medical expenditure and survival with integration of traditional Chinese medicine treatment in patients with heart failure: A nationwide population-based cohort study
}

\author{
Ming-Yen Tsai ${ }^{1,2}$, Wen-Long Hu ${ }^{2}$, Jen-Huai Chiang ${ }^{3,4}, \mathrm{Yu}^{-C h u e n ~ H u a n g}{ }^{5}$, Shih-Yu \\ Chen ${ }^{6}$, Yu-Chiang Hung ${ }^{2}$, Yung-Hsiang Chen ${ }^{1,7}$ \\ ${ }^{1}$ Graduate Institute of Integrated Medicine, College of Chinese Medicine, Research Center for Chinese Medicine \& Acupuncture, \\ China Medical University, Taichung, Taiwan \\ ${ }^{2}$ Department of Chinese Medicine, Kaohsiung Chang Gung Memorial Hospital and Chang Gung University College of Medicine, \\ Kaohsiung, Taiwan \\ ${ }^{3}$ Management Office for Health Data, China Medical University Hospital, Taichung, Taiwan \\ ${ }^{4}$ College of Medicine, China Medical University, Taichung, Taiwan \\ ${ }^{5}$ Department of Medical Research, China Medical University Hospital and School of Chinese Medicine, China Medical \\ University, Taichung, Taiwan \\ ${ }^{6}$ School of Chinese Medicine for Post Baccalaureate, I-Shou University, Kaohsiung, Taiwan \\ 7 Department of Psychology, College of Medical and Health Science, Asia University, Taichung, Taiwan \\ Correspondence to: Yu-Chiang Hung, email: hungyuchiang@gmail.com
}

Yung-Hsiang Chen, email: yhchen@mail.cmu.edu.tw

Keywords: traditional Chinese medicine, heart failure, NHIRD, medical expenditure, survival

Received: May 17, $2017 \quad$ Accepted: July 29, $2017 \quad$ Published: August 08, 2017

Copyright: Tsai et al. This is an open-access article distributed under the terms of the Creative Commons Attribution License 3.0 (CC BY 3.0), which permits unrestricted use, distribution, and reproduction in any medium, provided the original author and source are credited.

\section{ABSTRACT}

Background: No previous studies have evaluated the effects of traditional Chinese medicine (TCM) treatment on patients with heart failure (HF). Hence, in this study, we determined whether TCM treatment affects the healthcare burden and survival of HF patients.

Methods: Samples were retrieved from the registry of catastrophic illness patients of the Taiwan National Health Insurance Research Database (NHIRD). Based on a frequency (1:1) matched case-control design, patients with HF between 2000 and 2010 were designated as cases (TCM users) and controls (non-TCM users). TCM treatment for patients with HF was analyzed.

Results: Among these patients, 312 used TCM for HF treatment and exhibited significantly increased 5 -year survival $(p<.0001)$, with multivariate adjustment, compared with those without TCM use. Mean outpatient clinic visits at 1 year and 5 years after HF diagnosis were higher in TCM users, and accumulated medical costs were lower than in non-TCM users at 1 year. The hospitalization cost at 1-year follow-up was lower for TCM users than for non-TCM users. We found that, compared with non-TCM users, TCM users had an $86 \%$ reduction in risk of mortality in the compensated group, and a $68 \%$ reduction in the decompensated group receiving TCM treatment (aHR 0.32, 95\% CI 0.20-0.52). The hazard ratio (HR) of Chinese herbal medicine (CHM) users with HF was significantly lower than that of non-users (aHR $0.24,95 \% \mathrm{CI} 0.16-0.35$ ). We also analyzed the most commonly used herbal products as well as the HRs associated with their use, thus providing future research avenues.

Conclusions: This nationwide retrospective cohort study finds that combined therapy with TCM may improve survival in HF patients. This study also suggests that TCM may be used as an integral element of HF interventions on health care costs. 


\section{INTRODUCTION}

Heart failure (HF) is a common cause of morbidity and mortality [1-3]. The prevalence of HF is increasing worldwide due to both an aging population and significant advances in the management of associated comorbidities, such as ischemic heart disease, arrhythmia, diabetes mellitus, stroke, and hypertension $[4,5]$. Currently, $>5$ million American people are affected by HF, and 0.5 million patients are newly diagnosed with HF every year [6].

HF is also a leading use of medical resources, with significant healthcare costs driven by the intensive visits to clinics and extended hospital lengths of stay (LOS) [7]. HF imposes substantial costs, and total annual expenditures in the United States exceed $\$ 30.7$ billion [8]. A report from the Ministry of Health and Welfare of Taiwan estimated that the total annual expenditure associated with HF was (New Taiwan Dollars) NTD (1 NTD@0.329 U.S. dollars) 7.7 billion in 2009 [9]. Despite notable technological achievements and the exploitation of new drugs over recent decades, HF patients still have poor prognosis, with a 5-year survival rate of $50 \%$ after initial diagnosis [6].

Due to dissatisfaction with conventional western medication in treating HF [10], more and more HF patients are turning to complementary and alternative medicine (CAM) to improve the symptoms and signs of the disease [11]. Traditional Chinese medicine (TCM) is regarded as a CAM therapy in Western countries [12, 13]. However, it is a mainstream therapy in some Asian countries, such as Taiwan, Korea, and China. Some reports have expressed that a holistic approach of TCM could be employed in the treatment of HF [14], with the focus on the correction of overall disharmony of the human body by using multitargeted herbs to regulate and nourish qi-blood and yinyang $[15,16]$.

The National Health Insurance (NHI) is a universal health insurance program established in 1995 in Taiwan. It covers both western medicine and TCM [17]. With a high insured rate of 98-99 \%, the random sample that comprises the NHI research database (NHIRD) is representative of the general population and should allow a reasonably accurate assessment of the utilization of medical resources in Taiwan [18]. Therefore, the NHIRD provides an ideal platform for pharmacoepidemiological studies for understanding the benefits of TCM in Taiwan. Approximately $30 \%$ of Taiwanese people use TCM [19], and up to $70 \%$ of patients have received TCM for chronic diseases such as ischemic heart disease [20], ischemic stroke [21] and type II diabetes mellitus [22]. Our previous data from NHIRD showed that $78.5 \%$ of patients newly diagnosed with HF visited a TCM outpatient at least once in 2001-2010. The data also indicated the frequency and prescription patterns of Chinese herbal medicine (CHM), which could provide understanding of the practices of TCM practitioners in the treatment of HF [23]. However, no evidence to date has indicated that TCM could play a protective role in treating HF. We therefore conducted a nationwide population-based survey of HF patients to estimate the healthcare burdens of services for those who did and those who did not receive TCM treatment, and to identify the outcomes of the two populations.

\section{RESULTS}

From 2000 to 2010, 312 subjects met the criterion of TCM use for HF and were defined as TCM users, and an equal number of matched subjects were classified as non-TCM users. (Figure 1). The characteristics of patients in both groups are listed in Table 1. The percentages of the two groups at different ages were $1.6 \%$ in the $20-39$ year old group, $34.9 \%$ in the $40-64$ year old group, and $63.5 \%$ in the over 65 year old group. Females were slightly more represented than males. The mean duration of receiving TCM treatment after the diagnosis of HF was 414 days. Regarding the comorbidities of patients with HF, the incidences of most diseases, including hyperlipidemia, chronic obstructive pulmonary disease, and coronary artery disease, were higher in TCM users. In contrast, the incidences of diabetes mellitus and stroke were higher in non-TCM users.

Table 2 compares the clinical visits of outpatients and hospitalization of the TCM users and non-TCM users for periods of 1 and 5 years. TCM users had significantly more outpatient visits than did non-TCM users in the 1 and 5 year periods $(49 \pm 49$ vs. $23 \pm 20$, p-value $<.0001$; $188 \pm 202$ vs. $70 \pm 79, p<.0001)$. As compared with the HF without TCM treatment group, TCM users had lower medical expenditures $(53,602 \pm 75,379$ NTD vs. 64,154 $\pm 140,817$ NTD, $p<0.001$ ) for outpatient care within the 1-year after HF diagnosis. The medical expenditure for hospitalization in the first year after HF differed significantly between the two groups ( $p=0.0171$ ).

Table 3 shows the HR and details of the CHM most frequently prescribed by TCM practitioners for treating HF. The results show that Zhi-Gan-Cao-Tang (3,563 person-days) was the most frequently prescribed formula CHM, followed by Sheng-Mai-San (2,989 person-days) and Zhen-Wu-Tang (1,445 person-days). With regard to the single herbs for HF, Dan Shen (3,559 person-days) was the most common. San Qi (2,079 person-days) and Jie Geng (1,800 person-days) were the second and third most commonly used herbs, respectively. For most patients, receiving $\mathrm{CHM}$ was associated with significant reductions in HR.

A total of 614 patients diagnosed with HF were classified into two subgroups. A total of 31 death events occurred in 83 patients with decompensated HF who were prescribed TCM, whereas 13 death events occurred in the 229 subjects without decompensation who used TCM after HF diagnosis. We found that, compared with nonTCM users, TCM users in the compensated group tended 
to have a mortality rate lower than that of TCM users in the decompensated group (Table 4). In the compensated group, the HR of mortality of TCM users was 0.14 times lower than that of non-TCM users. In the decompensated group, patients who received TCM treatment also had a lower risk of mortality (aHR 0.32, with $95 \%$ CI $0.20-$ 0.52).

The difference in mortality between the TCM and non-TCM groups was also illustrated through a KaplanMeier survival graph, as shown in Figure $2(p<.0001)$.

\section{DISCUSSION}

This research is the first large-scale study on the economic burden and survival of TCM by patients with $\mathrm{HF}$ and was conducted by analyzing claims data from TCM and non-TCM clinic visits covered by the NHI in Taiwan. In a previous study [23], we investigated the frequency and prescription patterns of CHM for HF and found the same three most common CHMs and similar trends in the female gender and younger age groups of

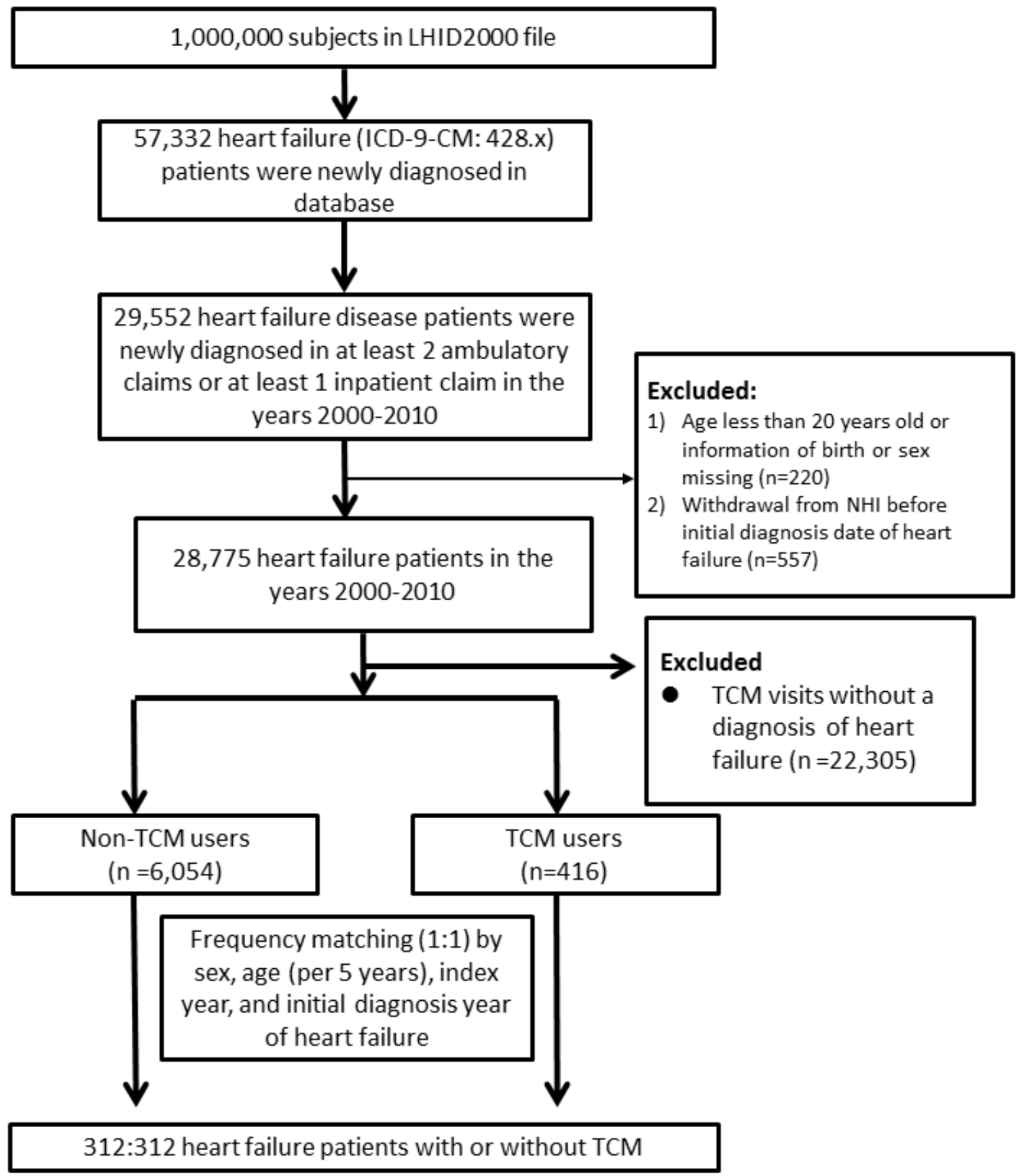

Figure 1: Flowchart of the recruitment of subjects who underwent TCM treatment from the 1 million random samples of the National Health Insurance Research Database (NHIRD) from 2000 to 2010 in Taiwan. 
Table 1: Characteristics of heart failure patients according to the use of TCM or not.

\begin{tabular}{|c|c|c|c|c|c|}
\hline \multirow{4}{*}{ Variable } & \multicolumn{4}{|c|}{ HF patients } & \multirow{4}{*}{$P$ value } \\
\hline & \multicolumn{4}{|c|}{ TCM users } & \\
\hline & \multicolumn{2}{|c|}{$\begin{array}{c}\text { No } \\
(n=312,50 \%)\end{array}$} & \multicolumn{2}{|c|}{$\begin{array}{c}\text { Yes } \\
(n=312,50 \%)\end{array}$} & \\
\hline & $n$ & $\%$ & $n$ & $\%$ & \\
\hline Sex & & & & & $0.99^{*}$ \\
\hline Female & 167 & 53.53 & 167 & 53.53 & \\
\hline Male & 145 & 46.67 & 145 & 46.47 & \\
\hline Age group & & & & & $0.99^{*}$ \\
\hline $20-39$ & 5 & 1.60 & 5 & 1.60 & \\
\hline $40-64$ & 109 & 34.94 & 109 & 34.94 & \\
\hline$>65$ & 198 & 63.46 & 198 & 63.46 & \\
\hline Mean \pm SD $($ years $)$ & \multicolumn{2}{|c|}{$68.51(12.03)$} & \multicolumn{2}{|c|}{$68.27(11.88)$} & $0.8028^{\mathrm{a}}$ \\
\hline \multicolumn{6}{|l|}{ Co-morbidity } \\
\hline Hyperlipidemia & 110 & 35.26 & 142 & 45.51 & $0.0090^{*}$ \\
\hline $\mathrm{DM}$ & 133 & 42.63 & 99 & 31.73 & $0.0049^{*}$ \\
\hline CAD & 141 & 45.19 & 166 & 53.21 & $0.0453^{*}$ \\
\hline COPD & 127 & 40.71 & 145 & 46.47 & $0.1462^{*}$ \\
\hline Stroke & 122 & 39.10 & 101 & 32.37 & $0.0794^{*}$ \\
\hline $\begin{array}{l}\text { The duration between onset of HF and the first visit to a } \\
\text { TCM clinic, days, mean (median) }\end{array}$ & \multicolumn{2}{|c|}{ - } & \multicolumn{2}{|c|}{$414(0)$} & \\
\hline
\end{tabular}

*Chi-Square test; ${ }^{\text {a }} \mathrm{t}$ test

The mean (median) of the follow-up period were 6.28 (5.62) years and 2.33 (0.91) years for TCM user and non-TCM users, respectively.

Abbreviation: TCM, traditional Chinese Medicine; DM, diabetes mellitus; CAD, coronary artery disease; COPD, Chronic Obstructive Pulmonary Disease; SD, standard deviation.

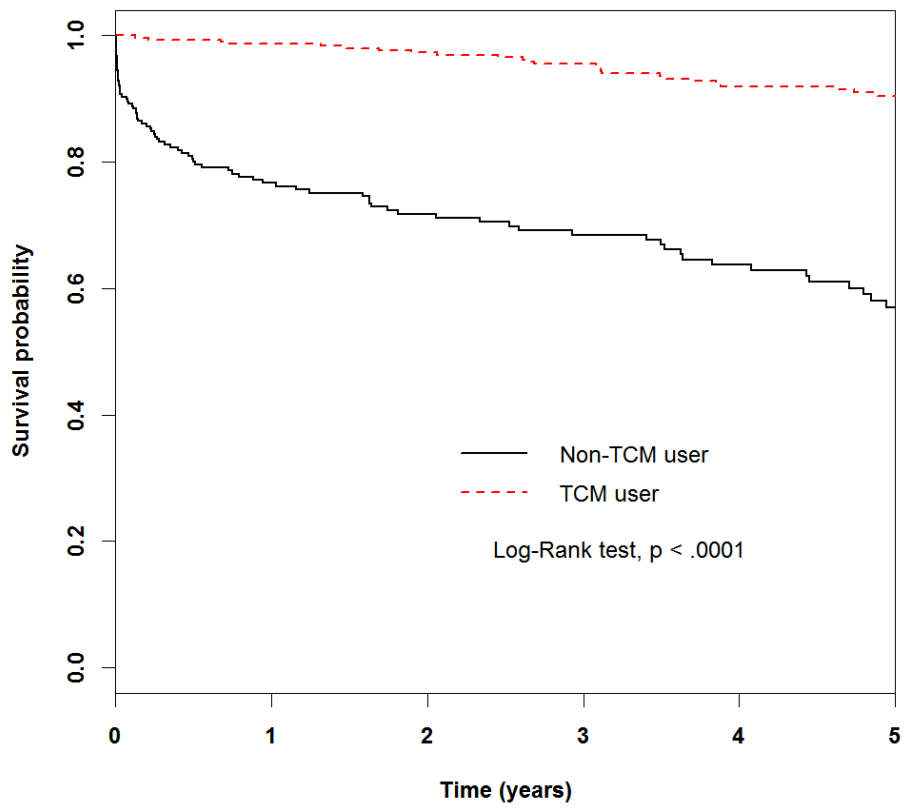

Figure 2: Kaplan-Meier curves of 5-year survival rate in patients with heart failure for TCM users and non-TCM users. (5-year survival: non-CHM user, 0.5692; CHM user, 0.9050). 
Table 2: Clinical visits for outpatient care and hospital length of stay, and their medical costs, for TCM and non-TCM users within 1 year and 5 years after diagnosis of heart failure.

\begin{tabular}{|l|c|c|c|c|c|}
\hline \multirow{2}{*}{\multicolumn{1}{|c|}{ Cost }} & \multicolumn{2}{c|}{ Non-TCM users } & \multicolumn{2}{c|}{ TCM users } & \multirow{2}{*}{ P value } \\
\cline { 2 - 5 } & $\boldsymbol{n}$ & Mean (SD) & $\boldsymbol{n}$ & Mean (SD) & \\
\hline Clinical visits & & & & & \\
\hline Outpatients care visits & 254 & $23.44(19.99)$ & 312 & $49.43(49.07)$ & $<.0001$ \\
\hline Hospital length of stay (days) & 130 & $60.55(209.06)$ & 96 & $39.63(132.70)$ & 0.3597 \\
\hline Cost & & & & & \\
\hline Outpatients care, NTD & 254 & $64,154(140817)$ & 312 & $53,602(75379)$ & $<.0001$ \\
\hline Hospitalization, NTD & 130 & $243,614(382984)$ & 96 & $139,888(265767)$ & 0.0171 \\
\hline 5 year & & & & & \\
\hline Clinical visits & & & & & \\
\hline Outpatients care visits & 257 & $70.12(78.80)$ & 312 & $188.08(202.39)$ & $<.0001$ \\
\hline Hospital length of stay (days) & 199 & $134.62(1097.03)$ & 201 & $108.54(368.48)$ & 0.7507 \\
\hline Cost & & & & & \\
\hline Outpatients care, NTD & 257 & $222,161(566458)$ & 312 & $238,376(427151)$ & 0.7051 \\
\hline Hospitalization, NTD & 199 & $315,813(548970)$ & 201 & $337,875(603776)$ & 0.7025 \\
\hline Clinical visits & & & & & \\
\hline
\end{tabular}

Abbreviate: TCM, traditional Chinese medicine; SD, standard deviation

$\S$ t-test

patients seeking TCM. However, the proportion of TCM utilization rate in this study is far below the previous one (6.43\% vs. $78.5 \%)$. This difference is due to the criterial design of the analyzed population for specific diseases in epidemiology or statistics. We knew that many registries in the NHI claims are primarily used for administrative billing and are not verified for scientific purposes [24]. Communicating with data must be done cautiously; for example, some HF patients registered in NHIRD had visited TCM clinics regardless of the real cause of HF. The possible overestimation of the TCM utilization rate is an important issue that needs to be emphasized. In addition, TCM physicians often use the symptoms of the ICD code to replace the patient's real diagnosis because of limitations in the health insurance payment system and medical prescription days. The accuracy of medical coding in the claims may affect the data validity because subjective opinions on diagnoses and prescriptions may vary across individual physicians in different clinical contexts [25].

The widespread uses of mortality-altering medications such as beta-blockers and ACE inhibitors have changed the prognosis of HF [26, 27]. However, the outcome of HF is grim. In a study of over 30,000 patients admitted with new-onset HF, the 1-year mortality rate was $30 \%$ [28]. An overview from the Framingham Heart Study, which used 50 years of follow-up data with HF, reported that the 5-year mortality rates in men and women were
$59 \%$ and $45 \%$, respectively [29]. Our analyses confirmed patients' diagnoses by using NHI claims and focused on records from outpatient files containing treatment by TCM clinicians. The results showed that only a smaller number of HF patients had received TCM therapy, which was far below the annual utilization rate of other diseases $(29-30 \%)$ [30]. However, the potential benefits of TCM treatment cannot be excluded. The improvement in survival can be seen in the Kaplan-Meier curve, which clearly illustrates that HF patients in the TCM group had longer survival times.

The majority of studies that have analyzed HF outcomes have focused on HF hospitalizations [31, 32]. HF patients who need admission to use pharmacologic and mechanical circulatory support to restore their compensatory mechanisms are likely to have had severe functional impairment (over 80\% in New York Heart Association (NYHA) classes III and IV) [31, 32]. Hospital admission for the intensive treatment of decompensated $\mathrm{HF}$ is an unfortunate certainty, regardless of etiology. In-hospital mortality for patients with decompensated HF ranges from $3-4 \%$, increasing to $10 \%$ at 90 days $[31,32]$. Although our previous study noted that chartlevel records are not available in the NHIRD for use as outcome indicators among patients with HF [31, 32], the current study found, from analyzing indirectly the codes of compromised respiratory function, that patients who used TCM treatment after mild to severe HF tended to have 
Table 3: HRs and 95\% CIs of mortality risk associated with the most-used herbal products as compared with nonCHM group among heart failure patients.

\begin{tabular}{|c|c|c|c|c|c|c|}
\hline \multirow{2}{*}{ Pin yin Nomenclature } & \multirow{2}{*}{ Scientific Name } & \multirow{2}{*}{\begin{tabular}{|c|} 
Accumulated \\
Person-Days
\end{tabular}} & \multirow{2}{*}{$n$} & \multirow{2}{*}{$\begin{array}{c}\text { Frequency of } \\
\text { Mortality }\end{array}$} & \multicolumn{2}{|c|}{ Hazard Ratio (95\% CI) } \\
\hline & & & & & Crude* & Adjusted $^{\dagger}$ \\
\hline Non-CHM group & & & 312 & 268 & 1.00 (reference) & 1.00 (reference) \\
\hline CHM group & & & 312 & 44 & $0.23(0.16-0.34)^{* * * *}$ & $0.24(0.16-0.35)^{* * * *}$ \\
\hline \multicolumn{7}{|l|}{\begin{tabular}{|l} 
Single herb \\
\end{tabular}} \\
\hline Dan Shen & Rx. Salviae Miltiorrhizae & 3,559 & 63 & 8 & $0.22(0.11-0.44)^{* * * *}$ & $0.25(0.13-0.51)^{* * * *}$ \\
\hline San Qi & Radix Notoginseng & 2,079 & 28 & 8 & $0.58(0.29-1.16)$ & $0.69(0.35-1.39)$ \\
\hline Jie Geng & Platycodonis Radix & 1,800 & 26 & 2 & $0.16(0.04-0.62)^{* * *}$ & $0.19(0.05-0.77)^{*}$ \\
\hline $\mathrm{Fu} \mathrm{Zi}$ & Aconiti Lateralis Preparata & 1,336 & 50 & 6 & $0.22(0.10-0.49)^{* * * *}$ & $0.27(0.12-0.60)^{* *}$ \\
\hline Zhi Ke & Fructus Aurantii & 1,334 & 10 & 2 & $0.34(0.09-1.37)$ & $0.39(0.10-1.55)$ \\
\hline Gui Zhi & Ramulus Cinnamomi & 1,064 & 39 & 4 & $0.21(0.08-0.55)^{* * *}$ & $0.24(0.09-0.63)^{* * * *}$ \\
\hline Huang Qi & Rx. Astragali & 988 & 47 & 7 & $0.28(0.13-0.58)^{* * *}$ & $0.31(0.15-0.64)^{* * * *}$ \\
\hline Dang Shen & Radix Codonopsis & 897 & 29 & 5 & $0.36(0.15-0.87)^{*}$ & $0.35(0.15-0.85)^{*}$ \\
\hline Wu Wei Zi & Fructus Schisandrae & 722 & 18 & 3 & $0.33(0.11-1.01)$ & $0.40(0.13-1.23)$ \\
\hline Ren Shen & Rx. Ginseng & 610 & 10 & 1 & $0.14(0.02-1.01)$ & $0.17(0.02-1.23)$ \\
\hline \multicolumn{7}{|l|}{ CHM formula } \\
\hline Zhi-Gan-Cao-Tang & $\begin{array}{l}\text { Rx. Glycyrrhizae Preparata, Rx. } \\
\text { Ginseng, Ram. Cinnamomi, Rx. } \\
\text { Rehmanniae, Tub. Ophiopogonis, } \\
\text { Colla Corii Asini, Sm. Cannabis, Rz. } \\
\text { Zingiberis Recens, Fr. Zizyphi Jujube, } \\
\text { White Wine }\end{array}$ & 3,563 & 73 & 12 & $0.28(0.16-0.49)^{* * * *}$ & $0.35(0.20-0.61)^{* * *}$ \\
\hline Sheng-Mai-San & $\begin{array}{l}\text { Rx. Ginseng, Tub. Ophiopogonis, Fr. } \\
\text { Schisandrae }\end{array}$ & 2,989 & 106 & 17 & $0.29(0.18-0.47)^{* * *}$ & $0.32(0.20-0.52)^{* * *}$ \\
\hline Zhen-Wu-Tang & $\begin{array}{l}\text { Rx. Aconiti Lateralis Preparata, Rz. } \\
\text { Atractylodis Macrocephalae, Poria, } \\
\text { Rz. Zingiberis Recens, Rx. Paeoniae } \\
\text { Alba }\end{array}$ & 1,959 & 45 & 6 & $0.26(0.11-0.57)^{* * *}$ & $0.26(0.12-0.59)^{* *}$ \\
\hline Suan-Zao-Ren-Tang & $\begin{array}{l}\text { Sm. Zizyphi Spinosae, Poria, Rx. } \\
\text { Anemarrhenae, Rx. Ligustici, Rx. } \\
\text { Glycyrrhizae }\end{array}$ & 1,445 & 7 & 0 & - & - \\
\hline Tian-Wang-Bu-Xin-Dan & $\begin{array}{l}R x . \text { Rehmanniae, Rx. Ginseng, } \\
R x . \quad \text { Asparagi, Rx. Ophiopogonis, } \\
R x . \quad \text { Scrophulariae, Rx. Salviae } \\
\text { Miltiorrhizae, Poria, Rx. Polygalae, } \\
\text { Rx. Angelicae Sinensis, Fr. } \\
\text { Schisandrae, Sm. Platycladi, Sm. } \\
\text { Zizyphi Spinosae, Rx. Platycodi, } \\
\text { Cinnabaris }\end{array}$ & 1,306 & 36 & 2 & $0.09(0.02-0.37)^{* * * *}$ & $0.11(0.03-0.44)^{* *}$ \\
\hline Xue-Fu-Zhu-Yu-Tang & $\begin{array}{l}\text { Sm. Persicae, Flos Carthami, Rx. } \\
\text { Angelicae Sinensis, Rz. Chuanxiong, } \\
\text { Rx. Paeoniae Rubra, Rx. Cyathulae, } \\
\text { Rx. Bupleuri, Rx. Platycodi, Fr. } \\
\text { Aurantii, Rx. Rehmanniae, Rx. } \\
\text { Glycyrrhizae } \\
\end{array}$ & 1,031 & 37 & 4 & $0.19(0.07-0.50)^{* * * *}$ & $0.22(0.08-0.58)^{* *}$ \\
\hline Ji-Sheng-Shen-Qi-Wan & $\begin{array}{l}R x . \quad \text { Rehmanniae Preparata, Fr. } \\
\text { Corni, Rx. Dioscoreae, Rz. Alismatis, } \\
\text { Poria, Cx. Moutan, Cx. Cinnamomi } \\
\text { Loureroi, Rx. Aconiti Lateralis } \\
\text { Preparata, Rx. Cyathulae, Sm. } \\
\text { Plantaginis }\end{array}$ & 999 & 33 & 8 & $0.46(0.23-0.93)^{*}$ & $0.43(0.21-0.86)^{*}$ \\
\hline Bu-Zhong-Yi-Qi-Tang & $\begin{array}{l}\text { Rx. Astragali, Rx. Ginseng, Rz. } \\
\text { Atractylodis Macrocephalae, Fried } \\
\text { Rx. Glycyrrhizae, Rx. Angelicae } \\
\text { Sinensis, Per. Citri Reticulatae, Rx. } \\
\text { Cimicifugae, Rx. Bupleuri } \\
\end{array}$ & 821 & 30 & 6 & $0.39(0.17-0.86)^{*}$ & $0.44(0.20-0.98)^{*}$ \\
\hline Si-Ni-Tang & $\begin{array}{l}\text { Rx. Aconiti Lateralis Preparata, Rz. } \\
\text { Zingiberis, Cx. Cinnamomi, Rx. } \\
\text { Glycyrrhizae Preparata } \\
\end{array}$ & 722 & 23 & 1 & $0.09(0.01-0.66)^{*}$ & $0.10(0.01-0.69)^{*}$ \\
\hline Liu-Wei-Di-Huang-Wan & $\begin{array}{l}\text { Rx. Rehmanniae Preparata, Fr. } \\
\text { Corni, Rx. Dioscoreae, Rz. Alismatis, } \\
\text { Poria, Cx. Moutan }\end{array}$ & 680 & 15 & 4 & $0.52(0.19-1.39)$ & $0.61(0.23-1.63)$ \\
\hline
\end{tabular}

Crude $\mathrm{HR}^{*}$ represented relative hazard ratio; Adjusted $\mathrm{HR} \uparrow$ represented adjusted hazard ratio: mutually adjusted for age, gender, hyperlipidemia DM, CAD, COPD and stroke in Cox proportional hazard regression.

$* p<0.05, * * p<0.01, * * * p<0.001$ 
lower risk of mortality. Therefore, to reduce mortality, the use of TCM treatment for patients with advanced stage HF could be considered.

In patients with $\mathrm{HF}$, all-cause hospitalization can be as high as $58 \%$ during 1-year follow-up and is associated with worse outcome [33]. Moreover, more frequent and longer hospitalizations would increase the inpatient mortality rate over time $[34,35]$. The greatest economic burden occurs within the first months after the first HF hospitalization or diagnosis [36], and patients face the highest financial costs of the disease in the first year [37]. Costs with hospitalization for decompensation reach approximately $60 \%$ of the total expenditures for the treatment of HF [31, 32]. Therefore, efforts should be made to reduce hospital LOS in order to improve outcomes and decrease medical expenditures. Our study of TCM users and non-users, as measured by the NHI, clearly shows beneficial economic results in lowering inpatient costs during 1-year follow-up.

However, it must be noted that we analyzed the medical expenditures of patients with HF, but not the costs due to the disease itself. Part of the calculated costs might not have been directly related to HF but secondary to the care of other ongoing co-morbidities. In addition, more evidence of TCM - not only hospital LOS, but also death event, re-hospitalization, and general modern lab indexes - should be explored in future research.

Our most significant finding was that the use of CHM was associated with a significant decrease in HR. The HR of the CHM group was $76 \%$ lower than that of the non-CHM group. Moreover, it was shown that most of the common CHM formulas or single herbs prescribed by TCM physicians decreased HR. Certain influences, such as the training background of physicians and characteristics of patients, cannot be ruled out in this type of retrospective study; however, this TCM syndrome differentiation and treatment supports the possibility of a causal relationship between the two. The fundamental problem in HF in TCM theory is the prolonged deficiency of heart qi and yang, which reduces the heart's ability to drive blood and transport fluid, leading to blood stasis and excessive fluid retention [38]. Therefore, the therapeutic principles are mainly to invigorate the heart yang-qi-specifically by accelerating blood circulation, liberating flow of the network vessels, and disinhibiting accumulated water [39].

Although clinical research on the effects of TCM on HF patients remains scarce, we propose several possible explanations for why a lower mortality is observed in patients with HF receiving TCM. First, patients with HF who undergo TCM treatment may have better knowledge or vigilance of disease prevention, both of which are considered to be protective factors against disease $[40,41]$. This improvement of the medical burden in TCM users in our study strengthens the possibility of a causal relationship between outpatient utilization rate and decreased HR. Second, some potential mechanisms by which CHMs act against HF have been established in previous studies. The potential mechanisms include improvement of cardiac function and histopathologic changes [42], sympathetic activation [43], oxidative stress of cardiovascular injury [44], immunity [45], and neurohormonal imbalance [46]. According to the results of this study, some CHMs were found to be beneficial for HF treatment (i.e., Zhi-Gan-Cao-Tang and Zhen-WuTang) and to improve the survival rate of HF patients. Third, patients with HF might have an increased risk of insomnia and sleep-related complications, such as fatigue, depression, and worsening functional performance [47]. Insomnia is a potential risk factor for HF [48], and SuanZao-Ren-Tang and Tian-Wang-Bu-Xin-Dan are commonly used in East Asia to improve insomnia and other mood problems [49]. Pharmacological studies have shown that both may exert beneficial effects on HF through stabilizing the central nervous system and reducing sympathetic overactivity $[50,51]$. Indirect treatments for sleep disorders may in turn lower the mortality of HF. Finally, according to a published study, more than half of the medical burden is applied to manage HF-related symptoms such as nausea, loss of appetite, fatigue, and general weakness [52]. These symptoms decrease quality of life, lower medical adherence, and reduce the intake of nutrients [53], and they also increase the risk of cardiovascular events [54]. Some CHM drugs for reinforcing qi (i.e., Bu-Zhong-YiQi-Tang, Sheng-Mai-San, Rx. Ginseng and Rx. Astragali) appear to be effective in improving the clinical sequelae of inadequate cardiac output and inefficient venous return [55-58]. According to a recent review, TCM and natural herbal medicines are promising therapeutic strategies for treating anorexia, malnutrition, or cachexia [59]. Additionally, CHM treatment has been associated with regulation of the catabolic state and cytokine dysfunction by inhibiting TNF- $\alpha$, IL- 6 , IL-10, and INF- $\gamma$ production [60]. Thus, by reducing the symptom burden in patients with HF through TCM treatment, clinical events including emergency department visits, hospitalizations, and longterm mortality in HF patients may be decreased.

Several limitations must be considered. First, the $\mathrm{NHI}$ program contains records for only CHMs prescribed by TCM physicians, not over-the-counter CHMs such as folk medicine and herbal decoction. Therefore, the utilization use of TCM may have been underestimated. Second, we used the ICD-9-CM codes recorded by clinicians to identify HF, but we had no physical symptom, radiological, or biochemical data to account for the severity of HF. Grading the severity of HF by additional codes of respiratory distress may produce overlaps with other common medical conditions, particularly COPD, and fail to detect worsening of HF symptoms without pulmonary edema. These shortcomings of the data can be overcome in future studies with the use of ICD-10-CM Terminology. Third, data on adverse drug reactions in this retrospective study were lacking, so we were unable to 
Table 4: Hazard Ratios and 95\% confidence intervals of mortality risk associated with TCM user among heart failure developing to decompensation or not.

\begin{tabular}{|l|c|c|c|c|}
\hline & $\boldsymbol{n}$ & Mortality & \multicolumn{2}{|c|}{ Hazard Ratio (95\% CI) } \\
\hline & & no & Crude* $^{*}$ & Adjusted $^{\dagger}$ \\
\hline Decompensated group & & & & 1 (reference) \\
\hline Non-TCM user & 139 & 54 & 1 (reference) & $0.32(0.20-0.52)^{* * *}$ \\
\hline TCM user & 83 & 31 & $0.39(0.24-0.61)^{* * *}$ & \\
\hline Compensated group & 173 & 36 & & 1 (reference) \\
\hline Non-TCM user & 229 & 13 & 1 (reference) & $0.14(0.07-0.28)^{* * *}$ \\
\hline TCM user & 139 & 54 & $0.14(0.07-0.27)^{* * *}$ & 0 \\
\hline
\end{tabular}

Crude $\mathrm{HR}^{*}$ represented relative hazard ratio;

Adjusted $\mathrm{HR} \uparrow$ represented adjusted hazard ratio: mutually adjusted for age, gender, hyperlipidemia DM, CAD, COPD and stroke in Cox proportional hazard regression.

$* p<0.05, * * p<0.01, * * * p<0.001$

evaluate the safety of TCM. In addition, much evidence has been reported on drug-herb interactions. For example, Zhen-Wu-Tang, Si-Ni-Tang, and Aconiti Lateralis Preparata may increase digoxin toxicity [61], and $R x$. Salviae Miltiorrhizae may interact with the anticoagulant action of warfarin $[62,63]$. However, such interactions seemed not to affect the clinical CHM prescription in our study. Fourth, we were unable to confirm whether the benefits of CHM were a direct result of the CHM used, a synergistic effect with cardiovascular drugs, or even just a result of the CHM reducing the adverse effects and consequently leading to a more successful prognosis. More epidemiological data on safety outcomes should be collected to clarify the causality in future studies.

In conclusion, this nationwide cohort study reveals that TCM treatment lowered the risk of death in patients with HF. Our findings also show that TCM appeared to reduce the healthcare system costs for HF. Study of the CHM formulas and single herbs commonly used to treat $\mathrm{HF}$ is warranted in higher-quality, randomized-controlled trials to validate these observational findings. The use of TCM is worthy of attention and further research.

\section{MATERIALS AND METHODS}

\section{Data sources}

Taiwan's compulsory universal NHI program was developed in 1995 by the National Health Insurance Administration, and it initially provided coverage to more than 23.03 million residents of Taiwan. By 2008, $>99 \%$ of the Taiwanese population was enrolled in the NHI program. Reimbursed TCM services include CHM, acupuncture, moxibustion, or manipulation in ambulatory clinics. The database contains all longitudinal reimbursement information, as well as gender, birth date, medications, and diagnosis codes based on the International Classification of Disease, Ninth Revision,
Clinical Modification (ICD-9-CM). This study was designed as a population-based study of a sample of one million subjects selected at random from the 22 million beneficiaries of the National Health Insurance scheme of Taiwan. The sampled patients exhibited no significant differences in age, sex, birth year, or average insured payroll-related amount from the general population. Because the NHIRD contains delinked secondary data for research, the need for informed consent was waived for this study. This study was approved by the Institutional Review Board of China Medical University (CMUH104REC2-115).

\section{Study population}

All patients 20 years old and above diagnosed with HF (ICD-9-CM: 428) between January 2000 and December 2010 were included. Inclusion criteria for the population with HF $(n=29,552)$ were at least two ambulatory visits or one inpatient claim with diagnosis of ICD-9-CM code 428 from 2000 to 2010. Patients were excluded if they were lost to follow-up in the NIH program for $>1$ year or had received TCM treatment before the initial date of HF but not in the tracking period. Patients having at least one medical record in a TCM outpatient clinic and the HF diagnostic code were defined as TCM users, whereas those who had no TCM outpatient records were defined as non-TCM users. For each TCM user, a control subject who was a non-TCM user was randomly selected by frequency-matching (1:1) with the case cohort to ensure that both had the same distributions for the strata of sex, age (per 5 years), and the time from the date of the first HF diagnosis to the index date.

\section{Covariate assessment}

The sociodemographic factors included age and sex. Age was divided into 3 groups: 20-39 years old, 40-64 years old, and $>65$ years old. Baseline comorbidities were 
considered present if ICD-9-CM codes appeared in at least two ambulatory claims or one inpatient claim before the initial diagnosis date of $\mathrm{HF}$, included diabetes mellitus (ICD-9-CM: 250), hyperlipidemia (272), coronary artery disease (410-414), chronic obstructive pulmonary disease (COPD; 490, 491, 492, 494 and 496), and stroke (430438). Decompensated HF, defined as a sudden or gradual worsening of HF signs and symptoms, is usually caused by rapid fluid accumulation in the lungs necessitating further hemodynamic and oxygen support [61]. Therefore, pulmonary edema (518.4) and respiratory failure (518.81) were selected to represent the decompensated state.

\section{Variables for expenditures and claim visits}

The database contained encounter forms based on the date of visit, medical facility visited, department visited, type of copayment, and billed and paid amounts. All visits within 1 year and 5 years after the index date were analyzed for expenditures as well as outpatient and inpatient claim visits.

\section{Statistical analysis}

Differences in demographic characteristics and comorbidities between the study and comparison cohorts were examined using the Chi-squared test for categorical variables and 2-sample t tests for continuous variables. The means of outpatient and inpatient visits and medical expenditures of TCM users and non-TCM users were compared with 2-sample t tests. In the future analysis, the risks of mortality for decompensated $\mathrm{HF}$ and compensated HF were calculated for TCM and non-TCM users. A univariate and multivariate Cox proportional hazards model was used to evaluate the hazard ratios (HRs) of TCM users on mortality. We estimated hazard ratios and their 95\% confidence intervals (CIs) by adjusting for age, gender, hyperlipidemia, DM, CAD, COPD, and stroke in Cox proportional hazard model regression.

Statistical analysis was performed and figures were created using SAS 9.4 (SAS Institute, Cary, NC) software. $\mathrm{P}<0.05$ in two-tailed tests indicated statistical significance.

\section{Author contributions}

MY Tsai and YC Huang designed the study. MY Tsai, WL Hu, and YC Hung acquired the data. JH Chiang analyzed the data. MY Tsai and SY Chen wrote the manuscript. YC Hung and $\mathrm{YH}$ Chen revised the manuscript. All authors read and approved the final manuscript.

\section{ACKNOWLEDGMENTS}

This study is supported in part by Taiwan Ministry of Health and Welfare Clinical Trial Center (MOHW106TDU-B-212-113004), China Medical University (CMU) Hospital, Taiwan Ministry of Science and Technology (MOST 104-2320-B-039-016-MY3), CMU under the Aim for Top University Plan of the Ministry of Education, Academia Sinica Taiwan Biobank Stroke Biosignature Project Taiwan Clinical Trial Consortium for Stroke (MOST 106-2321-B-039-005), Tseng-Lien Lin Foundation, Taichung, Taiwan, Taiwan Brain Disease Foundation, Taipei, Taiwan, and Katsuzo and Kiyo Aoshima Memorial Funds, Japan. We thank Prof Chung Y. Hsu for his enthusiastic help in this work.

\section{CONFLICTS OF INTEREST}

The authors have declared that no competing interests exist.

\section{REFERENCES}

1. Lin $\mathrm{YT}$, Lin $\mathrm{YH}, \mathrm{Wu} \mathrm{XM}, \mathrm{Ko} \mathrm{CL}, \mathrm{Yen} \mathrm{RF}$, Chen $\mathrm{YH}$, Hsu RB, Lee CM, Wang SS, Chen MF, Wu YW. The relationship between serum fibrosis markers and restrictive ventricular filling in patients with heart failure with reduced ejection fraction: A technetium-99m radionuclide ventriculography study. Oncotarget. 2017; 8: 2381-90. doi: 10.18632/oncotarget.13795.

2. Pang L, Hu J, Zhang G, Li X, Zhang X, Yu F, Lan Y, Xu J, Pang B, Han D, Xiao Y, Li X. Dysregulated long intergenic non-coding RNA modules contribute to heart failure. Oncotarget. 2016; 7: 59676-90. doi: 10.18632/ oncotarget.10834.

3. Cao Y, Shen T, Huang X, Lin Y, Chen B, Pang J, Li G, Wang Q, Zohrabian S, Duan C, Ruan Y, Man Y, Wang $\mathrm{S}$, et al. Astragalus polysaccharide restores autophagic flux and improves cardiomyocyte function in doxorubicininduced cardiotoxicity. Oncotarget. 2017; 8: 4837-48. doi: 10.18632/oncotarget.13596.

4. Mazurek JA, Jessup M. Understanding Heart Failure. Heart Fail Clin. 2017; 13: 1-19. doi: 10.1016/j.hfc.2016.07.001.

5. Larsson SC, Tektonidis TG, Gigante B, Akesson A, Wolk A. Healthy Lifestyle and Risk of Heart Failure: Results From 2 Prospective Cohort Studies. Circ Heart Fail. 2016; 9: e002855. doi: 10.1161/ CIRCHEARTFAILURE.115.002855.

6. Mozaffarian D, Benjamin EJ, Go AS, Arnett DK, Blaha MJ, Cushman M, de Ferranti S, Despres JP, Fullerton HJ, Howard VJ, Huffman MD, Judd SE, Kissela BM, et al. Heart disease and stroke statistics - 2015 update: a report from the American Heart Association. Circulation. 2015; 131: e29-322. doi: 10.1161/CIR.0000000000000152.

7. Fang J, Mensah GA, Croft JB, Keenan NL. Heart failure- 
related hospitalization in the U.S., 1979 to 2004. J Am Coll Cardiol. 2008; 52: 428-34. doi: 10.1016/j.jacc.2008.03.061.

8. Heidenreich PA, Albert NM, Allen LA, Bluemke DA, Butler J, Fonarow GC, Ikonomidis JS, Khavjou O, Konstam MA, Maddox TM, Nichol G, Pham M, Pina IL, et al. Forecasting the impact of heart failure in the United States: a policy statement from the American Heart Association. Circ Heart Fail. 2013; 6: 606-19. doi: 10.1161/ HHF.0b013e318291329a.

9. Shih ML, Chen HM, Chou FH, Huang YF, Lu CH, Chien HC. Quality of life and associated factors in patients with heart failure. [Article in Chinese]. Hu Li Za Zhi. 2010; 57: 61-71.

10. Sacks CA, Jarcho JA, Curfman GD. Paradigm shifts in heart-failure therapy — a timeline. N Engl J Med. 2014; 371: 989-91. doi: 10.1056/NEJMp1410241.

11. Yeh GY, Davis RB, Phillips RS. Use of complementary therapies in patients with cardiovascular disease. Am J Cardiol. 2006; 98: 673-80. doi: 10.1016/j. amjcard.2006.03.051.

12. Chen WT, Yang CL, Yin MC. Protective effects from Houttuynia cordata aqueous extract against acetaminopheninduced liver injury. Biomedicine (Taipei). 2014; 4: 5. doi: 10.7603/s40681-014-0005-2.

13. Wu MH, Lee TH, Lee HP, Li TM, Lee IT, Shieh PC, Tang CH. Kuei-Lu-Er-Xian-Jiao extract enhances BMP-2 production in osteoblasts. Biomedicine (Taipei). 2017; 7: 2. doi: 10.1051/bmden/2017070102.

14. Asokan Shibu M, Kuo WW, Kuo CH, Day CH, Shen CY, Chung LC, Lai CH, Pan LF, Vijaya Padma V, Huang CY. Potential phytoestrogen alternatives exert cardio-protective mechanisms via estrogen receptors. Biomedicine (Taipei). 2017; 7: 11. doi: 10.1051/bmden/2017070204.

15. Zhang P. Advantages, Disadvantages, and Trend of Integrative Medicine in the Treatment of Heart Failure. Cell Biochem Biophys. 2015; 72: 363-6. doi: 10.1007/s12013014-0466-7.

16. Layne K, Ferro A. Traditional Chinese medicines in the management of cardiovascular diseases: a comprehensive systematic review. Br J Clin Pharmacol. 2017; 83: 20-32. doi: 10.1111/bcp.13013.

17. Cheng SH, Chiang TL. The effect of universal health insurance on health care utilization in Taiwan. Results from a natural experiment. JAMA. 1997; 278: 89-93.

18. Lee YC, Huang YT, Tsai YW, Huang SM, Kuo KN, McKee M, Nolte E. The impact of universal National Health Insurance on population health: the experience of Taiwan. BMC Health Serv Res. 2010; 10: 225. doi: 10.1186/14726963-10-225.

19. Chen FP, Chen TJ, Kung YY, Chen YC, Chou LF, Chen FJ, Hwang SJ. Use frequency of traditional Chinese medicine in Taiwan. BMC Health Serv Res. 2007; 7: 26. doi: 10.1186/1472-6963-7-26.

20. Hung YC, Tseng YJ, Hu WL, Chen HJ, Li TC, Tsai PY,
Chen HP, Huang MH, Su FY. Demographic and Prescribing Patterns of Chinese Herbal Products for Individualized Therapy for Ischemic Heart Disease in Taiwan: PopulationBased Study. PLoS One. 2015; 10: e0137058. doi: 10.1371/ journal.pone.0137058.

21. Hung IL, Hung YC, Wang LY, Hsu SF, Chen HJ, Tseng YJ, Kuo CE, Hu WL, Li TC. Chinese Herbal Products for Ischemic Stroke. Am J Chin Med. 2015; 43: 1365-79. doi: 10.1142/S0192415X15500779.

22. Huang CY, Tsai YT, Lai JN, Hsu FL. Prescription pattern of chinese herbal products for diabetes mellitus in taiwan: a population-based study. Evid Based Complement Alternat Med. 2013; 2013: 201329. doi: 10.1155/2013/201329.

23. Tsai MY, Hu WL, Lin CC, Lee YC, Chen SY, Hung YC, Chen YH. Prescription pattern of Chinese herbal products for heart failure in Taiwan: A population-based study. Int $\mathrm{J}$ Cardiol. 2017; 228: 90-6. doi: 10.1016/j.ijcard.2016.11.172.

24. Kao CH. Author's Reply: National Health Insurance database in Taiwan. Eur J Intern Med. 2016; 31: e11-2. doi: 10.1016/j.ejim.2016.03.032.

25. Wu YT, Lee HY. National Health Insurance database in Taiwan: A resource or obstacle for health research? Eur J Intern Med. 2016; 31: e9-e10. doi: 10.1016/j. ejim.2016.03.022.

26. Garg R, Yusuf S. Overview of randomized trials of angiotensin-converting enzyme inhibitors on mortality and morbidity in patients with heart failure. Collaborative Group on ACE Inhibitor Trials. JAMA. 1995; 273: 1450-6.

27. Packer M, Bristow MR, Cohn JN, Colucci WS, Fowler MB, Gilbert EM, Shusterman NH. The effect of carvedilol on morbidity and mortality in patients with chronic heart failure. U.S. Carvedilol Heart Failure Study Group. N Engl J Med. 1996; 334: 1349-55. doi: 10.1056/ NEJM199605233342101.

28. Jong P, Vowinckel E, Liu PP, Gong Y, Tu JV. Prognosis and determinants of survival in patients newly hospitalized for heart failure: a population-based study. Arch Intern Med. 2002; 162: 1689-94.

29. Mahmood SS, Levy D, Vasan RS, Wang TJ. The Framingham Heart Study and the epidemiology of cardiovascular disease: a historical perspective. Lancet. 2014; 383: 999-1008. doi: 10.1016/S0140-6736(13)617523.

30. Ramani GV, Uber PA, Mehra MR. Chronic heart failure: contemporary diagnosis and management. Mayo Clin Proc. 2010; 85: 180-95. doi: 10.4065/mcp.2009.0494.

31. Dunlay SM, Redfield MM, Weston SA, Therneau TM, Hall Long K, Shah ND, Roger VL. Hospitalizations after heart failure diagnosis a community perspective. J Am Coll Cardiol. 2009; 54: 1695-702. doi: 10.1016/j. jacc.2009.08.019.

32. Joffe SW, Webster K, McManus DD, Kiernan MS, Lessard D, Yarzebski J, Darling C, Gore JM, Goldberg RJ. Improved survival after heart failure: a community-based 
perspective. J Am Heart Assoc. 2013; 2: e000053. doi: 10.1161/JAHA.113.000053.

33. Nichols GA, Reynolds K, Kimes TM, Rosales AG, Chan WW. Comparison of Risk of Re-hospitalization, AllCause Mortality, and Medical Care Resource Utilization in Patients With Heart Failure and Preserved Versus Reduced Ejection Fraction. Am J Cardiol. 2015; 116: 1088-92. doi: 10.1016/j.amjcard.2015.07.018.

34. Munir MB, Sharbaugh MS, Thoma FW, Nisar MU, Kamran AS, Althouse AD, Saba S. Trends in hospitalization for congestive heart failure, 1996-2009. Clin Cardiol. 2017; 40: 109-19. doi: 10.1002/clc.22638.

35. Gotsman I, Zwas D, Lotan C, Keren A. Heart failure and preserved left ventricular function: long term clinical outcome. PLoS One. 2012; 7: e41022. doi: 10.1371/journal. pone.0041022.

36. Korves C, Eldar-Lissai A, McHale J, Lafeuille MH, Hwa Ong S, Sheng Duh M. Resource utilization and costs following hospitalization of patients with chronic heart failure in the US. J Med Econ. 2012; 15: 925-37. doi: 10.3111/13696998.2012.685136.

37. Farre N, Vela E, Cleries M, Bustins M, Cainzos-Achirica M, Enjuanes C, Moliner P, Ruiz S, Verdu-Rotellar JM, Comin-Colet J. Medical resource use and expenditure in patients with chronic heart failure: a population-based analysis of 88195 patients. Eur J Heart Fail. 2016; 18: 1132-40. doi: 10.1002/ejhf.549.

38. Liang D, Zhang M. The thinking on TCM differential treatment of congestive heart failure. J Tradit Chin Med. 2000; 20: 44-7.

39. Tang WH, Huang Y. Cardiotonic modulation in heart failure: insights from traditional Chinese medicine. J Am Coll Cardiol. 2013; 62: 1073-4. doi: 10.1016/j. jacc.2013.05.028.

40. Shih CC, Liao CC, Su YC, Tsai CC, Lin JG. Gender differences in traditional Chinese medicine use among adults in Taiwan. PLoS One. 2012; 7: e32540. doi: 10.1371/ journal.pone.0032540.

41. Tu CC, Li CS, Liu CM, Liu CC. Comparative use of biomedicine and Chinese medicine in Taiwan: using the NHI Research Database. J Altern Complement Med. 2011; 17: 339-46. doi: 10.1089/acm.2010.0200.

42. Ma RG, Wang CX, Shen YH, Wang ZQ, Ma JH, Huang LS. Effect of Shenmai Injection on ventricular diastolic function in patients with chronic heart failure: An assessment by tissue Doppler imaging. Chin J Integr Med. 2010; 16: 1735. doi: 10.1007/s11655-010-0173-1.

43. Xie ZX, Wang SY, Liang ZJ, Zeng LB. Effect of Zhenwu Tang Granule on pressure-overloaded left ventricular myocardial hypertrophy in rats. World J Emerg Med. 2010; 1: 149-53.

44. Fu XJ, Liu HB, Wang P, Guan HS. A study on the antioxidant activity and tissues selective inhibition of lipid peroxidation by saponins from the roots of Platycodon grandiflorum. Am J Chin Med. 2009; 37: 967-75. doi: 10.1142/S0192415X09007375.

45. Fu S, Zhang J, Menniti-Ippolito F, Gao X, Galeotti F, Massari M, Hu L, Zhang B, Ferrelli R, Fauci A, Firenzuoli F, Shang H, Guerra R, et al. Huangqi injection (a traditional Chinese patent medicine) for chronic heart failure: a systematic review. PLoS One. 2011; 6: e19604. doi: 10.1371/journal.pone.0019604.

46. Jiang B, Chen J, Xu L, Gao Z, Deng Y, Wang Y, Xu F, Shen X, Guo DA. Salvianolic acid B functioned as a competitive inhibitor of matrix metalloproteinase-9 and efficiently prevented cardiac remodeling. BMC Pharmacol. 2010; 10: 10. doi: 10.1186/1471-2210-10-10.

47. Tsuchihashi-Makaya M, Matsuoka S. Insomnia in Heart Failure. Circ J. 2016; 80: 1525-6. doi: 10.1253/circj.CJ-160501.

48. Tofield A. Insomnia linked to increased risk of heart failure. Eur Heart J. 2013; 34: 1771.

49. Chen YL, Lee CY, Huang KH, Kuan YH, Chen M. Prescription patterns of Chinese herbal products for patients with sleep disorder and major depressive disorder in Taiwan. J Ethnopharmacol. 2015; 171: 307-16. doi: 10.1016/j.jep.2015.05.045.

50. Yi PL, Lin CP, Tsai CH, Lin JG, Chang FC. The involvement of serotonin receptors in suanzaorentanginduced sleep alteration. J Biomed Sci. 2007; 14: 829-40. doi: 10.1007/s11373-007-9197-8.

51. Yi PL, Tsai CH, Chen YC, Chang FC. Gamma-aminobutyric acid (GABA) receptor mediates suanzaorentang, a traditional Chinese herb remedy, -induced sleep alteration. J Biomed Sci. 2007; 14: 285-97. doi: 10.1007/s11373-0069137-z.

52. Alpert CM, Smith MA, Hummel SL, Hummel EK. Symptom burden in heart failure: assessment, impact on outcomes, and management. Heart Fail Rev. 2017; 22: 2539. doi: 10.1007/s10741-016-9581-4.

53. Sciatti E, Lombardi C, Ravera A, Vizzardi E, Bonadei I, Carubelli V, Gorga E, Metra M. Nutritional Deficiency in Patients with Heart Failure. Nutrients. 2016; 8. doi: 10.3390/nu8070442.

54. Son YJ, Song EK. High nutritional risk is associated with worse health-related quality of life in patients with heart failure beyond sodium intake. Eur J Cardiovasc Nurs. 2013; 12: 184-92. doi: 10.1177/1474515112443439.

55. Choi KT. Botanical characteristics, pharmacological effects and medicinal components of Korean Panax ginseng $\mathrm{C}$ A Meyer. Acta Pharmacol Sin. 2008; 29: 1109-18. doi: 10.1111/j.1745-7254.2008.00869.x.

56. Wang XQ, Takahashi T, Zhu SJ, Moriya J, Saegusa S, Yamakawa J, Kusaka K, Itoh T, Kanda T. Effect of Hochuekki-to (TJ-41), a Japanese Herbal Medicine, on Daily Activity in a Murine Model of Chronic Fatigue Syndrome. Evid Based Complement Alternat Med. 2004; 1: 203-6. doi: 10.1093/ecam/neh020. 
57. Xian S, Yang Z, Lee J, Jiang Z, Ye X, Luo L, Jin L, Yang $\mathrm{T}, \mathrm{Ye} \mathrm{S}, \mathrm{Lu} \mathrm{D}$. A randomized, double-blind, multicenter, placebo-controlled clinical study on the efficacy and safety of Shenmai injection in patients with chronic heart failure. J Ethnopharmacol. 2016; 186: 136-42. doi: 10.1016/j. jep.2016.03.066.

58. Yang QY, Chen KJ, Lu S, Sun HR. Research progress on mechanism of action of Radix Astragalus in the treatment of heart failure. Chin J Integr Med. 2012; 18: 235-40. doi: 10.1007/s11655-012-1022-1.

59. Ming-Hua C, Bao-Hua Z, Lei Y. Mechanisms of Anorexia Cancer Cachexia Syndrome and Potential Benefits of Traditional Medicine and Natural Herbs. Curr Pharm Biotechnol. 2016; 17: 1147-52.

60. Shin HY, Shin CH, Shin TY, Lee EJ, Kim HM. Effect of bojungikki-tang on lipopolysaccharide-induced cytokine production from peripheral blood mononuclear cells of chronic fatigue syndrome patients. Immunopharmacol Immunotoxicol. 2003; 25: 491-501. doi: 10.1081/IPH120026435 .
61. Chen XW, Sneed KB, Pan SY, Cao C, Kanwar JR, Chew $\mathrm{H}$, Zhou SF. Herb-drug interactions and mechanistic and clinical considerations. Curr Drug Metab. 2012; 13: 640-51.

62. Nutescu EA, Shapiro NL, Ibrahim S, West P. Warfarin and its interactions with foods, herbs and other dietary supplements. Expert Opin Drug Saf. 2006; 5: 433-51. doi: 10.1517/14740338.5.3.433.

63. Tsai HH, Lin HW, Chien CR, Li TC. Concurrent use of antiplatelets, anticoagulants, or digoxin with Chinese medications: a population-based cohort study. Eur J Clin Pharmacol. 2013; 69: 629-39. doi: 10.1007/s00228-0121359-6. 